\title{
THE ECONOMIC EXPLANATION OF INCLUSIVE DESIGN IN DIFFERENT STAGES OF PRODUCT LIFE TIME
}

\author{
Li, Fang (1,3); Dong, Hua (2) \\ 1: College of Architecture and Urban Planning, Tongji University; 2: College of Design and Innovation, \\ Tongji University; 3: Institute of International Exchange, Shanghai Open University
}

\begin{abstract}
The static data obtained from user research are not sufficient to accurately reflect the change of the user's needs and capabilities in different contexts. Not paying enough attention to the economic feasibility of design solutions makes inclusive design face challenges in commercialization. In this paper, the user's demand is regarded as a function of the dynamic interaction between the user's characteristics and the environment. The inclusion problem is defined from an economic perspective. By distinguishing the stages before and after the delivery of a product, different economic properties of the product are defined. Then the two stages are analysed from the perspective of investment and consumption respectively, and the competition criterion of inclusivity distribution and the reasons for exclusion are deduced. According to the causes of different problems in the two stages, the research direction of inclusive solutions is pointed out, and the economical sustainability of inclusive design is analysed. This paper emphasizes that the goal of inclusive design lies not only in the partial and temporary elimination of exclusion, but also in how to distribute the freedom of choice.
\end{abstract}

Keywords: Inclusive design, Design theory, Design methodology, User centred design, Design economics

Contact:

Li, Fang

Tongji University

College of Architecture and Urban Planning

China, People's Republic of

franklifang@tongji.edu.cn

Cite this article: Li, F., Dong, H. (2019) 'The Economic Explanation of Inclusive Design in Different Stages of Product Life Time', in Proceedings of the 22nd International Conference on Engineering Design (ICED19), Delft, The Netherlands, 5-8 August 2019. DOI:10.1017/dsi.2019.244 


\section{INCLUSIVE DESIGN AND DESIGN EXCLUSION}

British Standards Institute (BSI) defines inclusive design as: 'The design of mainstream products and/or services that are accessible to, and usable by, as many people as reasonably possible ... without the need for special adaptation or specialised design (BSI, 2005)'. Design exclusion occurs when the capability required for using a product (in a broad sense) exceeds the user's actual capability (Clarkson and Keates, 2002). The purpose of inclusive design is often to eliminate the barriers and exclusion, so that products, services and built environment could meet as diverse needs as possible. To some people, inclusive design appears to be a utopian ideal, and it is regarded as a value-driven design philosophy rather than an approach to achieve its goals.

As human differences are common, it is almost impossible to provide a product designed for everyone (Steinfeld and Tauke, 2002). There are also views that the design effort in the barrier-free area is still an incidental charitable act and a welfare issue. What should be done is to divide people's needs into different functional aspects and then find appropriate values to cover each extreme of these aspects (Wijk, 2002). Matteo Bianhin and Ann Heylighen emphasized the concepts of design fairness (2017) and design justice (2018), which helps expand the theoretical boundary of inclusive design. They use John Rawls' justice theory to transform the contradiction of inclusivity issues from the usability of a single item to the distribution of usability in society. However, this distribution still depends on the standards set by the judiciary and it is difficult to evaluate whether such distribution is fair or unfair. Although usability does not cover the full scope of design inclusion/exclusion, the idea of usability distribution provides a helpful perspective, which reveals the resource attributes of usability and the possibility of exploring the method of its distribution in an economically compliant manner.

In this paper, we take an economics viewpoint, and suggest that design in a broad sense can be regarded as an arrangement of supply for meeting specific needs. Accordingly, we consider design exclusion as: existing mainstream products, services and environments fail to satisfy certain needs from (potential) users.

\section{ISSUES AND RESEARCH QUESTIONS}

There are obvious barriers, such as disability; and older people often have one or more types of physical capability loss or decline, which leads to difficulties when using products designed only for 'ordinary people' or 'mainstream people' (Hitchcock et al., 2001). Many studies have focused on this type of barriers. In order to design solutions for such problems, researchers tend to believe that the main challenge for designers is that they are not familiar with the ability range and behaviour of disabled and elderly users. Therefore, user research has been highly valued, and empathic design (Strickfaden and Devlieger, 2011), participatory design (Frauenberger et al., 2011) and co-design (Munthe-Kaas, 2015) have become important methods to understand user capabilities and needs. However, users have their own motives, experiences and expectations, different people always have different interpretations that designers can't find, understand or control (Crilly et al., 2008).

Here we would like to point out that design in a broad sense can be regarded as an arrangement of supply for specific needs, regardless of whether the supply is related to practical functions, emotional needs or technical requirements. Supply and demands are fundamental issues in economics. Generally speaking, the products, services and built environment and many of their attributes involved in inclusive design have two characteristics: i.e. having some is better than having none, and having more is better than having less. That is, when individuals make choices, they will always choose the former between having some and having not, having more and having less. From public buildings and facilities to personal products and services, from barrier-free design to ease of use and fault-tolerance, it is always 'better than none' and 'better than less', so they can be considered as economic goods.

The supply mode of economic goods can be roughly divided into two categories, the planned mode and the market mode. The former may have various pre-designed distribution rules depending on the situation, while the latter is mainly determined by the market and the one with the highest price wins. Regardless of the planned mode and the market mode, as long as the supply is limited, competition is unavoidable, but the specific rules and methods of competition may differ (Cheung, 2014). For example, when enrolments of good schools are based on entrance examination results, students will have to study hard to win the competition (i.e. places). When school enrolments are based on catchment areas, the competition will turn to the real estates within the catchment areas of good 
schools. The definition of economic goods has determined that competition is the basic means to distribute economic goods. Consequently, participating in the competition means you must always have the ability to pay, more or less.

As an additional attribute of economic goods, inclusiveness is mainly determined by two factors, one is the degree of user satisfaction - usefulness, and the other is the ease of access to such satisfaction usability. Usefulness is related to the matching degree of user's needs, which determines the maximum potential value of a product. Usability is closely related to the matching degree of user's characteristics and abilities. It determines how much discount should be paid when potential value is transformed into real value. Taking clothing as an example, factors such as the type, style and design determine the matching degree of clothing to consumers' needs, while the size is one of the basic indicators of clothing usability.

Due to the diversity of users' needs, characteristics and abilities, a series of questions arise in this regard:

- How will resources be attracted to the supply of product usefulness and usability?

- How is the usability of products distributed?

- What factors influence the distribution mechanism?

We try to find out to what extent the introduction of economic principles and methods in design research can help answer these questions. First of all, we can infer the competition criterion of inclusivity distribution under the condition of definite limitation. At the same time, we give an economic definition of some key elements in inclusive design for further analysis and calculation. Secondly, we define competition criteria through inferring the behaviour of stakeholders, applying proven economic tools to analyse inclusive values, establishing value models, and understanding how resources will be used and how users will respond and choose. Finally, we discuss the limitations in the economic interpretation and measurement of inclusive design.

\section{INCLUSIVENESS IN THE PERSPECTIVE OF ECONOMICS}

To explain inclusiveness from an economic perspective, it is necessary to clarify its definition first. The BSI definition of inclusive design is given at the beginning of this paper, from which we can derive design exclusion as: some people's needs are not considered from the existing mainstream products, services and environment, and they are not satisfied. The possible controversy is that few products and services can really satisfy everyone, which seems to rationalize design exclusion. Obviously, if the supply is limited, there will always be some unmatched demands (unmet needs). The key question here is: which demands excluded from the supply should be considered as an issue of exclusion?

In the design field, it is inevitable that we discuss inclusion and exclusion with subjective value judgement. Most designs are tailored to specific needs and capability requirements. Correspondingly, exclusion is almost universally present. Exclusion in design often implies that it 'should not have been excluded'. For example, the usability of a product or environment for disabled people or older people 'should not' be ignored. However, the decision of 'should' and 'should not' tends to be a value judgment.

On the one hand, inclusive design hopes to bridge the inequality gap caused by diversity and enable as many users as possible to gain the value and experience provided by the design; on the other hand, the universal design makes diversified users reduce diversity to universality and reduce the richness of choice through a materialized uniqueness (Winance, 2014). Due to the ubiquitous competition, the generalized design that typical inclusive design tends to adopt has both advantages and disadvantages compared with customized design: the former is advantageous in achieving the scale effect due to the cover of a wider range of users, while the latter is easier to meet the needs of specific user groups. When different individuals with common needs compete for a limited supply, individuals at competitive disadvantage are often excluded due to various factors.

Of course, value judgment has its own important humanistic and social significance, and this paper tries to explore the general law of inclusion and exclusion in the real society and its impact on design. To study inclusiveness from the perspective of economics, we must put aside the judgment of 'should' and 'should not' for the time being, detach 'demand' and 'supply', which has become inexhaustible without considering the cost, study the inclusion and exclusion from the law of human behaviour, and focus on analysing the mechanism that affects inclusion/exclusion and comparing different situations. 


\subsection{The dynamic change of demands}

In spite of various methods, the user data (including user capabilities and desires) obtained through user research in design studies are either qualitative or quantitative. It usually comes from interviews, surveys, behaviour observations and insights into the results of experiments. For example, the role of personas in the product design process is presented in a descriptive way (Marshall et al., 2015). Some studies using quantitative tools will have certain values or ranges, such as the demand analysis of people who frequently visit Taiwan's urban parks (Wu and Song, 2017). Although the part of these user data which is used to describe the user's ability and characteristics cannot avoid fluctuations in different contexts, it will maintain a certain degree of stability. In contrast, the dynamic change of user's demand is much more affected by constraints. The hot weather will have an impact on the ice cream sales of convenience stores, the congestion on the road and the purpose of travel will have an impact on the choice of different travel means ...the effect of all kinds of external environment is hard to enumerate. In addition, the user's demand is also affected by internal factors, e.g. the growth and decline of desire, the decrease of satisfaction, the accumulation of fatigue and the restriction of capability, all of which influence the change of demand at all times. Therefore, since the demand changes with the change of constraints and conditions, we should consider the demand of the user as a function of the interaction between user's own characteristics and the environment, and the demand at any moment is always changing dynamically with the instability of the environment and user's own state. Therefore, it is difficult to accurately describe and truly understand the user's nonquantifiable demand; and traditional research methods only capture inputs and insights under static conditions that are unrelated to the user's willingness to pay the price.

Economists use the demand curve (Figures 1 and 2) to reflect the situation; consumers' demands change with price. The demand curve is generally an indifference curve downward to the right (Figures 1 and 2). The indifference curve originally refers to a curve in which consumers hold different combinations of two commodities with the same utility under the premise of constant budget and price (Samuelson and Nordhaus, 2012). If we replace one of the commodities with a currency or universal equivalent that can be used to exchange other commodities, we can get a certain commodity demand curve - consumers choose to hold different proportions of commodities and currencies, while the choice of all points on the curve has no difference in advantages and disadvantages for consumers' choices. The transaction cost and holding cost in reality will affect whether the demand is exhaustive and fully satisfied (Figure 1 vs. Figure 2). If we study the real demand from the perspective of individual differences, the highest price and demands individuals are willing and able to bear for a specific demand are usually relatively limited (Figure 1).

Our hypothesis is that the user demand obtained by design research had better be a similar curve or function, which represents the change of a user's demand with respect to constraints or alternative choices, rather than a set of fixed values.

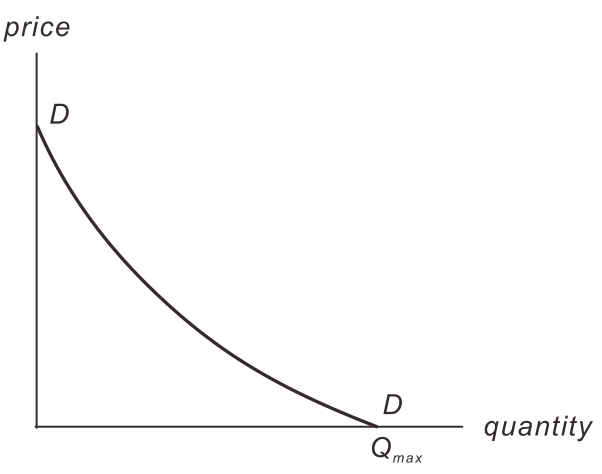

Figure 1. Limited demand curve with full satisfaction

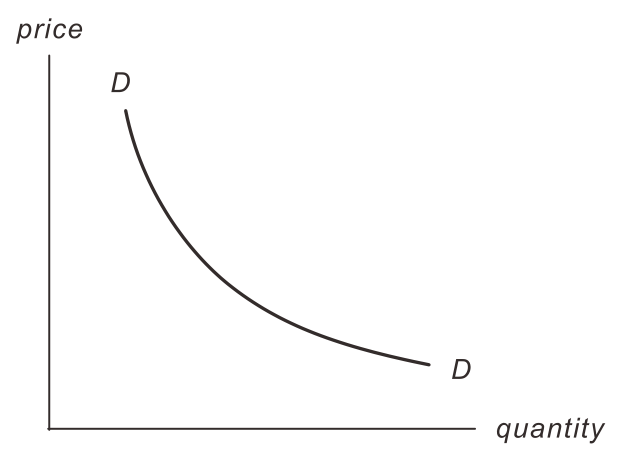

Figure 2. Unlimited demand curve without full satisfaction

\subsection{Two stages of the user's participating in product life time}

The lifetime of a product can be traced back to the beginning of research and development (R\&D) and manufacturing, until it is eventually discarded or recycled. It is the whole process in which a product wants to create value by satisfying the needs of consumers. The process can be divided into five stages 
(Figure 3) with four nodes: production, release, delivery and retirement. Design is in the R\&D stage, but designers need to pay close attention to and serve the needs of the next four stages.

Inclusive design emphasizes its user-centred perspective. Although for customized products and services, users may participate in the R\&D stage, for most mass-produced products, the intersection with each end-user mainly occurs after the product has been developed and manufactured and before it is abandoned. This user-involved period can be divided into two stages if we use product delivery as the demarcation point. The first is the distribution and investment stage before the delivery of the product, that is, the consumer's choice and investment of the product; the second is after delivery; consumers will use the products as users in the consumption and use stage.

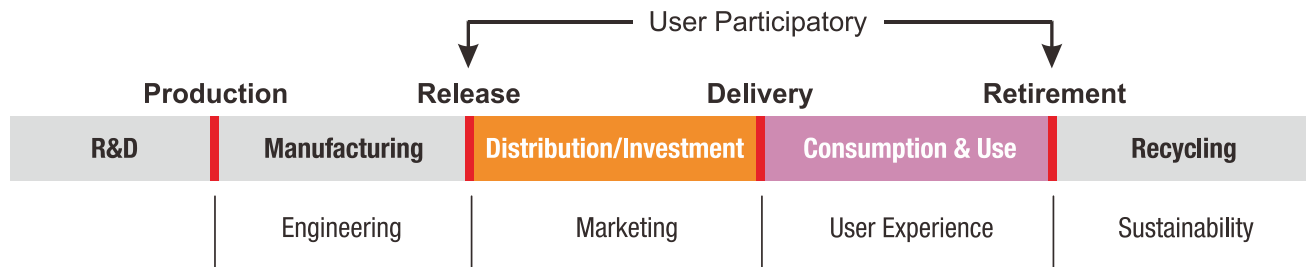

Figure 3. Five stages in life time of mass production product

Adam Smith points out that commodities have two kinds of value: one is the use value, and the other is the exchange value. The use value is the highest price consumers are willing to pay, and the exchange value is usually the market price. Karl Marx emphasizes that the use value is made by utility and realized only by use or consumption. According to the expected utility theory (Neumann and Morgenstern, 1944), the consumers' choice reflected in the demand curve of the distribution and investment stage is actually the result of a comparison between the current market price and consumers' expectation of the net use value (rather than the actual use value). If the expected value is higher than the market price, they will obtain more, and if it is lower, they will buy less. In fact, we cannot accurately predict the ultimate use value, and our value judgment for the same amount of gains and losses are often different (Kahneman and Tversky, 1979). In many cases we do not even know the real market price, and the actual purchasing investments observed in the trading behaviour are based on the comparison of value expectations with what we think is a fair price in our mental account (Thaler, 2008). Utility is determined by the actual use, and its discrepancy with conscious utility inevitably leads to the distortion of the expected value, which in turn has an impact on the choice. On the other hand, the investment of the product is the premise of the use. If the product cannot win the choice of consumers under constraints, even the opportunity to prove and realize the use value will not exist.

The competition for the distribution and investment of products is essentially to ensure the supply of demands during the use stage. For example, the purchase of a car is for the convenience of transportation while traveling, the download and installation of an application is for the purpose of providing appropriate functions for devices such as mobile phones or computers when needed. We can regard the acquisition of products as an investment to guarantee the supply and save the cost of transactions in the use stage, and the products purchased in the investment stage are essentially aimed at the exchange value and asset properties. Such assets will be consumed in the use stage under the obligation of performance. Therefore, the use value of the products plays a key role in the consumption stage. This definition can also apply to disposable products and temporary services that are instantly available, but the two stages of these products and services are closely linked. Some products and services are not distributed by market, such as gifts from relatives and friends, public goods, public services and public spaces provided free of charge by the government or institutions. Although there is no obvious comparison and investment stage for users of these products and services, they can be directly analysed and treated as in the use stage, but it should be noted that their asset properties still exist objectively.

The competition for demand and supply at the distribution/investment stage is an investment; and it is the competition of the distribution of assets and usage rights. In the investment stage, competition is the main means of supply distribution; we need to explore the impact of users on the competitiveness of supply differences in terms of inclusiveness. In the stage of consumption, users have obtained some degree of guarantee for the right to use the goods. The focus of our research will be on the fluctuating factors of supply, users' demands and abilities in different contexts.

The significance of making a clear distinction between the investment stage and the use stage lies in the extremely 'inclusive' consideration of the differences between the two stages of inclusiveness 
issues themselves, thus giving us the flexibility to use different tools and methodologies for analysis. A common controversy is how to evaluate the inclusiveness of high-end products such as Dyson's electric appliances and the iPhone. On the one hand, from the perspective of user experience, not only Dyson's outstanding design and the ecosystem established by iPhone and iOS are favoured by their core users, but also their thoughtful consideration of accessibility which has greatly reduced the barriers for both disabled and non-disabled users to use. However, on the other hand, the high prices have excluded many people in worse economic conditions. If we study the two stages separately, the answers to such questions will be readily solved.

\subsubsection{The distribution/investment stage}

As shown in Figure 4, the demand curve D reflects the consumers' expectation of the use value under different demands at a certain moment. We can regard the supply of the maximum demand on the demand curve as the consumers have reached the state of complete satisfaction. Under the mode of market distribution, the price is the main criterion to measure consumers' ability. When there are massive consumers competing for the supply, the demand of a single consumer is not enough to affect the market and can only be used as a passive receiver of the market price. For a single consumer at this time, the supply curve $\mathrm{S}$ is approximately a horizontal line, that is, no matter what the consumer's demand is, the market will provide products at a stable price $\mathrm{P}$, and the intersection point $\mathrm{E}$ between it and the consumer's demand curve is the equilibrium point. Above the supply curve, the marginal use value is always greater than the market price, so the consumer is always willing to buy more products until the marginal use value of consumer is equal to the market price at the equilibrium point. When the marginal use value continues to decrease from the equilibrium point, the consumer will not only get no profit from the supply, but also will add losses due to the excessive cost, so he or she will no longer have the motivation to obtain the supply. Therefore, if the transaction price is replaced by a broader concept of cost and the demand curve reflecting the relationship between quantity and price, then exclusion, the core issue of inclusive design, can be defined and assumed more precisely: the choice that consumers give up for some reasons is the exclusion, which is shown in Figure 4 as a region surrounded by E, Q and Qmax.

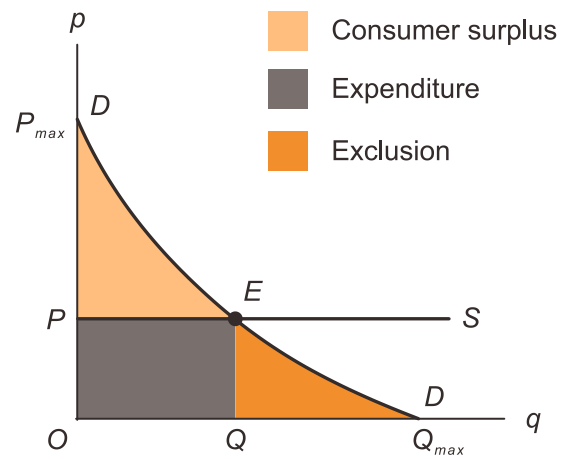

Figure 4. Exclusion in a fully competitive market

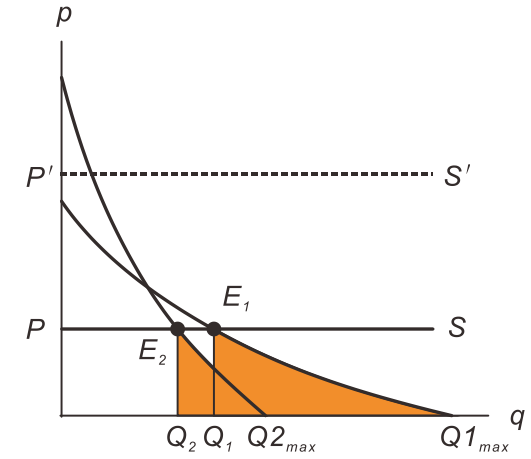

Figure 5. Differences in the demands and exclusion of different users

The area between the demand curve and the quantity-price coordinate axis (PmaxOQmax in Figure 4) reflects the total demand of the user for the products under ideal conditions and is also the maximum user value that the products can create. The distribution on demand depicted by communism is the typical representative of this ideal state: under the premise of extremely rich material, consumers can achieve complete satisfaction of demand without paying any price for it. If this goal is achieved, the issue of inclusiveness will cease to exist, as the supply is assumed to be able to meet any demand. However, at least in today's reality, from a general point of view, limited resources and productivity are fundamental constraints, so competition is inevitable and the cost cannot be constant equal to zero. As long as the cost is greater than zero, part of the demand must be abandoned and exclusion must exist. At a certain cost:

users' actual realized value $=$ maximum user value - exclusion $=$ expenditure + consumer surplus 
However, the utopian concept of infinite supply points out a way to promote inclusiveness and reduce exclusion: if we can continuously increase the supply level of a product, the degree of competition for that product will decrease, thus causing the price to fall. With the demand curve unchanged, the area of exclusion will decrease as the equilibrium point of the supply and demand moves down to the right, thus increasing the actual realized value for users.

It can be seen that in the distribution/investment stage, the satisfaction degree of the established demand mainly depends on the price determined by competition, that is, the cost of demand realization. There are diversities in abilities and needs between individuals, and different demanders have different demand curves, which means that the competitiveness of different demand for the same supply also varies. In a fully competitive market, although different demanders have to accept a uniform market price, each individual's choice is based on different marginal use values and different total costs (Figure 5), thus resulting in different degrees of exclusion. At different price levels, exclusion differences can lead to completely different demand satisfaction. When the supply curve in Figure 5 changes from $S$ to $S^{\prime}$, that is, when the price rises from $P$ to $\mathrm{P}^{\prime}$, some demanders still have a certain degree of demand satisfaction, and some demanders have been completely excluded.

\subsubsection{The consumption and use stage}

In the consumption and use stage, when consumers have acquired the ownership or use right of products or services, they have changed to users. This means that it has become a sunk cost, regardless of whether there is a price for acquiring to products or services. No matter whether the product will be used later or what its value is, the cost of obtaining the product cannot be recovered. At the same time, since the type and quantity of supply have been determined, we can even think that consumers have obtained a certain degree of supply guarantee for the product or service in its life cycle through the purchasing action or other distribution methods. Therefore, although the supply guarantee is largely determined by the competition in the distribution stage, the expectation of the supply in the use stage is relatively stable and clear, that is, to release the obtained supply in the consumption stage. Otherwise, once the expected shortage of supply arises, the user will restart the acquisition of products until they get the supply guarantee that meets the demand again or replace them with alternative products. Nevertheless, supply shortages due to poor design or other reasons are still very common in the use stage, and this shortage increases the exclusion before the user can regain the supply guarantee. It should be pointed out that although we use the same term 'use value', the specific meaning of the use value of products in the investment stage and use stage differs. The use value in the investment stage is determined by the user's demand for the usability of the product in the usage stage. It is the discount of all usability valuations in the investment stage, that is, the valuation by consumers or users at the time for purchase decision. The use value in the use stage is determined by the usefulness of the product in each use, which needs to be determined independently each time, and may vary greatly in different times and scenarios.

If the issue of inclusiveness in the distribution/investment stage is mainly the contradiction between specific products/services and differentiated user capabilities/demands, then in the consumption and use stage, since the supply and use demands have been preliminarily matched through market selection, the main factor that leads to exclusion in the consumption and use stage is the change of supply and demand matching condition in different time and contexts.

For products, services and built environments, the important value for users in the use stage is usefulness. Here 'usefulness' refers not only to practicality and functionality, but also to other factors such as aesthetics, emotion, and experience. The realization of usefulness depends on matching the supply with the demand, and matching the preference and the ability of the user. Generally, the design of products and services will meet the needs and preferences of the target users as much as possible and adapt to the users' capabilities, so as to win the favour and choice of users in the investment stage, and create a good experience for users in the use stage. But when the supply and output of products and services or the demand preferences and capabilities of users change in the use stage, the original, relatively stable matching may be destroyed, which will lead to exclusion when the degree of change is large enough. When the deviation between the supply and the demand is larger, both sides may seek a new combination, that is, to introduce new suppliers or demanders into the competition for supply and demand resources, resulting in the exclusion of the less competitive users in the gap between the supply and the demand. 


\subsection{The economical sustainability of inclusive design}

From the perspective of supply, finding and satisfying demands is a self-serving economic behaviour of enterprises. If it is profitable, any demands will be found out and fulfilled sooner or later, then even leading to supply-side competitions. Therefore, in theory, any demands have the opportunity and possibility to be satisfied. When talking about why we need inclusive design, moral and political factors such as human rights and equal opportunities often become the primary arguments. There is no doubt that the diversity of human groups should be respected, but it is such a wide range of differences that we have to face. Each individual's needs have the opportunity to be met, but each individual has different resources, abilities and willingness to pay the price for their needs. This objective reality limits the opportunity and ability of individual needs to be satisfied, and causes competition among individuals under resource constraints in the demand-side. As the existence of such competition is often neglected, the vulnerable groups/needs in the competition are excluded from the opportunities.

The competition between individuals and needs is comprehensive and complicated. The user capability mentioned in the traditional inclusive design is only one of the causes and manifestations of competitive weakness. When the supply curve crosses the demand curve, the supply cost will swallow up the profits and generate losses, making the supply difficult to sustain economically (Figure 6). In the case of fixed cost (Figure 7), with the increase of inclusive supply, the supply cost per unit decreases with the amortization of fixed cost. When the unit cost reaches the first break-even point E1, the continuous increase of supply will begin to generate positive income. On the other hand, the variable cost will rise with the increase of the supply, the amortization bonus of fixed costs will be offset slowly, and the increased variable cost to meet non-common demand will lead the unit cost to be suppressed first and then gradually raised, reaching the break-even point E2. At this time, the supply cost of inclusion is again equivalent to the income, while the overall income of inclusion is maximized, and to increase inclusion is no longer cost-effective.

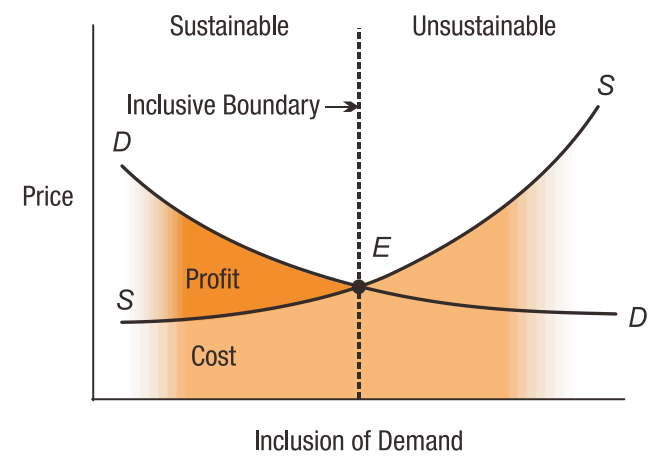

Figure 6. Inclusive design value model without fixed cost

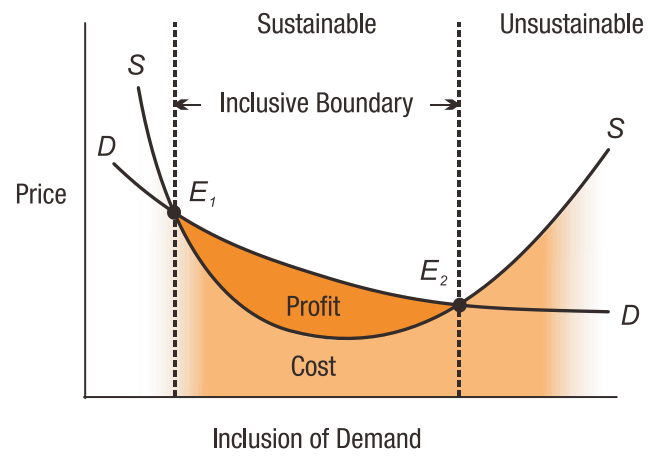

Figure 7. Inclusive design value model with fixed cost amortization

It is not difficult to understand that any factor which can have an impact on the matching of the demand and the supply may change the cost of meeting the demand, which is sustainable only if the cost of meeting the demand is lower than the price that the demander is willing to pay. The one-sided pursuit of the ability to accommodate the weak is often difficult to obtain the recognition of commercial supply. However, the existing theories of universal design and inclusive design lack consideration of design as an economic activity.

\section{CONCLUSIONS AND DISCUSSIONS}

In this paper, the authors give the definitions of inclusiveness/exclusion from the perspective of economics and makes it measurable. From the definition and analysis, we can infer that exclusion will occur as long as the supply equilibrium is not completely sufficient for the individual demander. Inclusion and exclusion are the two sides of a coin. The key to improving inclusiveness depends not only on increasing the supply of usability, accessibility and user experience, but also on improving the distribution of the supply.

For inclusive design research, the stages before and after the delivery of products or services should be distinguished. Before delivery, the main properties of products and services are assets and equities. The insufficient supply in this distribution stage is mainly due to the competition caused by the shortage of 
supply. Because there is always competition in economic goods and diversities among users are widespread, exclusion is a very common and basic phenomenon, which is almost inevitable. But as long as the price of supply is not higher than the highest price that users are willing to pay, the inevitability of exclusion does not prevent users from obtaining inadequate demand satisfaction through inclusive design, which we call effective demand satisfaction. However, this kind of partial satisfaction requires a better distribution in order to achieve overall inclusiveness. After delivery, the main properties of products and services are the providers of function and emotional value. The exclusion at this stage is subject to the competition results at the distribution stage on the one hand, and mainly comes from the contextual fluctuations in supply and demand on the other hand. Therefore, the inclusive design for this stage should consider and respond to the dynamic change in demand.

In the context of idealized design research, researchers often unconsciously assume an ideal society similar to that depicted by Utopia and communism. However, in reality, the compensation for the lack of supply by productivity development is far from being achieved. Even if there is overproduction, it is also partial and structural. Therefore, providing inclusiveness by expanding supply is bound to face constraints brought by economical sustainability. Due to the existence of competition, there is no absolute freedom in the world. From the perspective of human behaviour, any demand is a trade-off relative to other needs. Because each individual's ability to pay for different needs varies greatly, it makes the degree of freedom of choice, satisfaction or exclusion of each person very different. Therefore, the goal of inclusive design is not only to eliminate exclusion locally and temporarily, but also to allocate the freedom of choice reasonably.

In contrast, optimizing the distribution of usability and user experience is a potential inclusive design method. Designers need to tap the resources with comparative advantages of different users. Providing multi-dimensional competitive choices in the distribution/investment stage can reduce the polarization of resource allocation caused by a single competitive criterion, so that supply can more effectively accommodate the diversity of demands. In the consumption and use stage, due to the widespread diversities of users and fluctuations in users' needs and capabilities, identifying and responding to a specific need of specific users in a specific context through user sensitive design may be the effective means to improve inclusion.

\section{REFERENCES}

Bianchin, M. and Heylighen, A. (2018), “Just design”, Design Studies, Vol. 54, pp. 1-22, available: http://dx.doi.org/10.1016/j.destud.2017.10.001.

Bianchin, M. and Heylighen, A. (2017), "Fair by design. Addressing the paradox of inclusive design approaches", Design Journal, Vol. 20, pp. S3162-S3170, available: http://dx.doi.org/10.1080/14606925.2017.1352822.

British Standards Institution (2005), New British Standard addresses the need for inclusive design, available: https://www.bsigroup.com/en-GB/about-bsi/media-centre/press-releases/2005/2/New-British-Standardaddresses-the-need-for-inclusive-design/ [accessed 2018-05-05].

Cheung, N.C. (2014), Economic Explanation, CITIC Publishing Group Co., Ltd, Beijing.

Clarkson, P.J. and Keates, S. (2002), "Quantifying design exclusion”, In: Keates, S., Langdon, P., Clarkson, P.J., Robinson, P. (eds) Universal Access and Assistive Technology, Springer, London, pp. 23-32, available: http://doi.org/10.1007/978-1-4471-3719-1_3

Crilly, N., Maier, A. and Clarkson, P.J. (2008), "Representing Artefacts as Media: Modelling the Relationship Between Designer Intent and Consumer Experience”, International Journal of Design, Vol. 2 No. 3.

Frauenberger, C., Good, J. and Keay-Bright, W. (2011), "Designing technology for children with special needs: bridging perspectives through participatory design”, Codesign-International Journal of Cocreation in Design and the Arts, vol. 7 No. 1, pp. 1-28, available: http://dx.doi.org/10.1080/15710882.2011.587013.

Hitchcock, D.R., Lockyer, S., Cook, S. and Quigley, C. (2001), “Third age usability and safety - an ergonomics contribution to design", International Journal of Human-Computer Studies, Vo. 55 No. 4, pp. 635-643, available: http://dx.doi.org/10.1006/ijhc.2001.0484.

Kahneman, D. and Tversky, A. (1979), "Prospect Theory: An Analysis of Decision Under Risk", Econometrica, Vol. 47 No. 2, pp. 263-291.

Marshall, R., Cook, S., Mitchell, V., Summerskill, S., Haines, V., Maguire, M., Sims, R., Gyi, D. and Case, K. (2015), "Design and evaluation: End users, user datasets and personas", Applied Ergonomics, Vol. 46, Part B, pp. 311-317, available: http://dx.doi.org/10.1016/j.apergo.2013.03.008.

Marshall, R., Cook, S., Mitchell, V., Summerskill, S., Haines, V., Maguire, M., Sims, R., Gyi, D. and Case, K. (2015), "Design and evaluation: End users, user datasets and personas", Applied Ergonomics, Vol. 46, Part B, pp. 311-317, available: http://dx.doi.org/10.1016/j.apergo.2013.03.008. 
Mises, L. V. (2015), Human Action: A Treatise on Economics, translated by Xia, D.P., Shanghai Social Sciences Press, Shanghai.

Munthe-Kaas, P. (2015), “Agonism and co-design of urban spaces”, Urban Research and Practice, Vol. 8 No. 2 , pp. 218-237, available: http://dx.doi.org/10.1080/17535069.2015.1050207.

Neumann, J.V. and Morgenstern, O. (1944), Theory of Games and Economic Behavior, Princeton University Press, Princeton.

Samuelson, P.A. and Nordhaus, W.D. (2012), Microeconomics, Nineteenth Edition ed., translated by Xiao, C., Beijing, Posts and Telecom Press.

Steinfeld, E. and Tauke, B. (2002), "Universal Designing” in Christophersen, J., ed., Universal Design: 17 Ways of Thinking and Teaching, Husbanken, Norway, pp. 165-189.

Strickfaden, M. and Devlieger, P. (2011), "Empathy through Accumulating Techne: Designing an Accessible Metro", Design Journal, Vol. 14 No. 2, pp. 207-229, available: http://dx.doi.org/10.2752/175630611x12984592780041.

Thaler, R.H. (2008), "Mental Accounting and Consumer Choice", Marketing Science, Vol. 27 No. 1, pp. 15-25, available: http://dx.doi.org/10.1287/mksc.1070.0330.

Wijk, M. (2002), "If Anything, Call It Ergonomics - in Search for a Word in a World Called Science" in Christophersen, J., ed., Universal Design: 17 Ways of Thinking and Teaching, Husbanken, Norway, pp. 81-104.

Winance, M. (2014), "Universal design and the challenge of diversity: reflections on the principles of UD, based on empirical research of people's mobility", Disability and Rehabilitation, Vol. 36 No. 16, pp. 1334-1343, available: http://dx.doi.org/10.3109/09638288.2014.936564.

Wu, K.-C. and Song, L.-Y. (2017), “A case for inclusive design: Analyzing the needs of those who frequent Taiwan's urban parks”, Applied Ergonomics, Vol. 58, pp. 254-264, available: http://dx.doi.org/10.1016/j.apergo.2016.06.015. 